\title{
Multimodal imaging for detection and segmentation of Barrett's esophagus-related neoplasia using artificial intelligence
}

The early diagnosis of cancer in Barrett's esophagus is crucial for improving the prognosis. However, identifying Barrett's esophagus-related neoplasia (BERN) is challenging, even for experts [1]. Fourquadrant biopsies may improve the detection of neoplasia, but they can be associated with sampling errors. The application of artificial intelligence (AI) to the assessment of Barrett's esophagus could improve the diagnosis of BERN, and this has been demonstrated in both preclinical and clinical studies [2,3].

In this video demonstration, we show the accurate detection and delineation of BERN in two patients ( $>$ Video 1 ). In part 1 , the Al system detects a mucosal cancer about $20 \mathrm{~mm}$ in size and accurately delineates the lesion in both white-light and narrow-band imaging. In part 2, a small island of BERN with high-grade dysplasia is detected and delineated in whitelight, narrow-band, and texture and color enhancement imaging. The video shows the results using a transparent overlay of the mucosal cancer in real time as well as a full segmentation preview. Additionally, the optical flow allows for the assessment of endoscope movement, something which is inversely related to the reliability of the Al prediction. We demonstrate that multimodal imaging can be applied to the $\mathrm{Al}$-assisted detection and segmentation of even small focal lesions in real time.

Endoscopy_UCTN_Code_TTT_1AO_2AM

Funding

This work was funded by the Bavarian State Ministry of Sciences, Research and the Arts and supported by the Bavarian Academic Forum (BayWISS) - Doctoral Consortium "Health Research."

\section{Competing interests}

The authors declare that they have no conflict of interest.

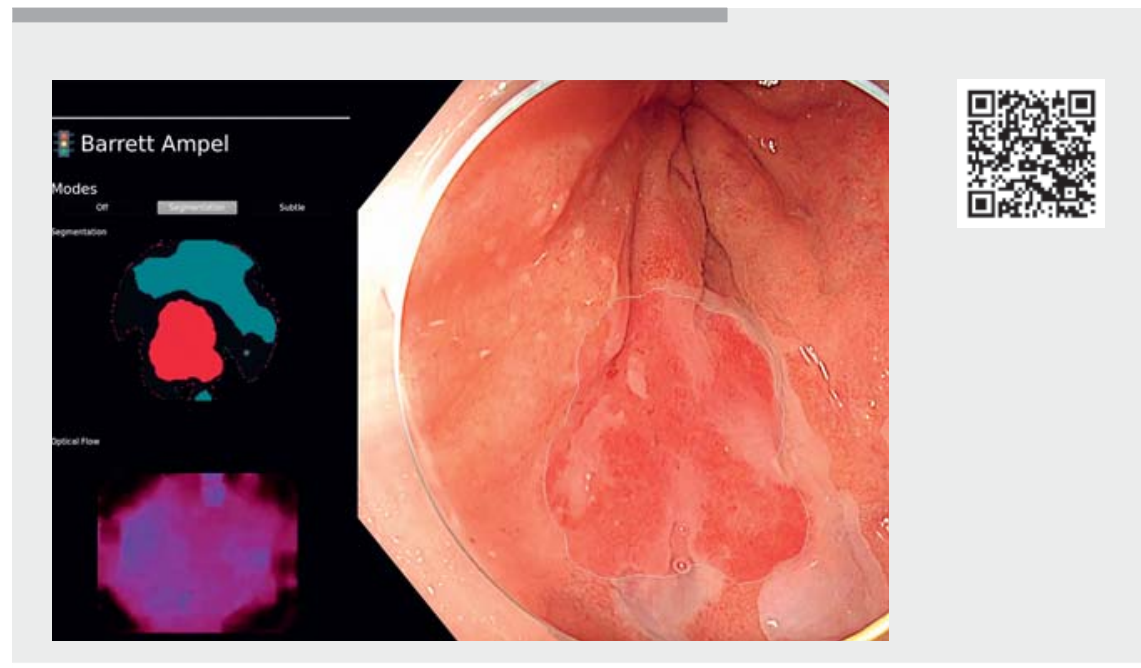

Video 1 Artificial intelligence (AI)-assisted detection and segmentation of Barrett's esophagus-related neoplasia. The Al system accurately detects and delineates even a small island of dysplasia in real-time multimodal imaging endoscopic examinations. NBI, narrowband imaging; TXI, texture and color enhancement imaging.

The authors

Alanna Ebigbo ${ }^{1}$, Robert Mendel ${ }^{2}$, Andreas Probst $^{1}$, Michael Meinikheim ${ }^{1}$, Michael $\mathrm{F}$. Byrne $^{3}$, Helmut Messmann ${ }^{1}$, Christoph Palm²

1 Department of Gastroenterology, Universitätsklinikum Augsburg, Augsburg, Germany

2 Regensburg Medical Image Computing Lab, Ostbayerische Technische Hochschule Regensburg, Regensburg, Germany

3 Department of Gastroenterology, Vancouver General Hospital, University of British Columbia, Vancouver, Canada

\section{Corresponding author}

\author{
Alanna Ebigbo, MD \\ Department of Gastroenterology, \\ Universitätsklinikum Augsburg, \\ Stenglinstr. 2, 86156 Augsburg, Germany \\ alanna.ebigbo@gmx.de
}

References

[1] Sharma P, Bergman JJ, Goda K et al. Development and validation of a classification system to identify high-grade dysplasia and esophageal adenocarcinoma in Barrett's esophagus using narrow-band imaging. Gastroenterology 2016; 150: 591-598

[2] Ebigbo A, Mendel R, Probst A et al. Real-time use of artificial intelligence in the evaluation of cancer in Barrett's oesophagus. Gut 2020; 69: 615-616

[3] de Groof AJ, Struyvenberg MR, van der Putten J et al. Deep-learning system detects neoplasia in patients with Barrett's esophagus with higher accuracy than endoscopists in a multistep training and validation study with benchmarking. Gastroenterology 2020; 158: 915-929

\section{Bibliography}

Endoscopy 2022; 54: E587

DOI 10.1055/a-1704-7885

ISSN 0013-726X

published online 21.12.2021

(c) 2021. Thieme. All rights reserved.

Georg Thieme Verlag KG, Rüdigerstraße 14, 70469 Stuttgart, Germany 